http://dx.doi.org/10.5007/2175-8085.2018v21n1p01

\title{
Ciclos político-orçamentários nos municípios de Santa Catarina
}

Political budget cycles in Santa Catarina's municipalities

\author{
Jonatan Lautenschlage \\ jlauten@eeg.uminho.pt \\ Universidade do Minho (NIPE)
}

\begin{abstract}
Resumo: Este trabalho examina a existência de ciclos político-orçamentários ao nível dos municípios do Estado brasileiro de Santa Catarina. Foram utilizados dados anuais de 292 municípios catarinenses entre 2003 e 2014, para que fossem realizados diversos testes empíricos. Encontrou-se indícios da existência de manipulações nos investimentos, nas receitas tributárias e nas operações de crédito em períodos eleitorais. Os resultados sugerem que no ano subsequente às eleições municipais, há uma redução das despesas totais, dos investimentos, dos tributos arrecadados e há uma melhora no saldo fiscal. Evidenciou-se, também, que o gênero, a formação superior e o alinhamento político ao governador de estado, têm influência na condução da política físcal ao nível dos municípios catarinenses, assim como o nível do produto, a sua variação e as características demográficas.
\end{abstract}

Palavras-chave: Ciclos político-orçamentários; Eleições; Governos locais

Abstract: This work examines the existence of political budget cycles at the municipal level of the Brazilian state of Santa Catarina. We used annual data for 292 municipalities of Santa Catarina between 2003 and 2014, to implement several empirical tests. We found evidence of changes in investments, in taxes revenue, credit operations and the budget balance in election periods. The results suggest the personal characteristics of the mayor (gender, superior education, and the alignment with the governor), influence the fiscal policy in the municipalities of Santa Catarina. The data also suggest a fiscal consolidation after elections. Total expenditures and investments decrease, and the budget balance increase in the year after elections.

Key-words: Political budget cycles; Elections; Local government

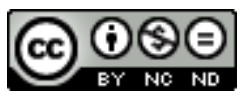

\section{INTRODUÇÃO}

A economia e a política estão intimamente ligadas, especialmente porque quem comanda as políticas macroeconômicas - fiscal, monetária e cambial - são justamente os políticos. Essa prerrogativa pode gerar algum enviesamento, especialmente no período pré-eleitoral, dado que os governantes podem utilizar os mecanismos de política econômica como uma 
artimanha para ganhar eleições, ou seja, os políticos são oportunistas e podem fazer uso dos meios disponíveis para se manterem no poder.

Essa percepção levou estudiosos a elaborarem teorias a fim de estabelecer uma relação entre a política e a economia. É no âmbito da Economia Política onde ocorre o maior debate sobre o processo de decisão eleitoral, bem como a interação entre política e economia e suas consequências tanto para a política, quanto para a economia. Uma vez que é no escopo desta literatura que a Teoria dos Ciclos Político-Orçamentários (CPO) se encontra e tenta explicar atitudes econômicas tomadas pelos agentes políticos. A análise dessa problemática torna-se ainda mais relevante num momento no qual os políticos brasileiros enfrentam uma crise de credibilidade, por parte dos cidadãos.

No Brasil há três esferas administrativas: Governo Federal ou União, Estados e Municípios e essa divisão administrativa possibilita a existência de CPO nos três níveis de governo. O objetivo desse trabalho é analisar se existe, nos municípios catarinenses, um perfil oportunista por parte dos prefeitos e se determinados traços pessoais (ideologia, gênero, formação superior, impedimento de concorrer à reeleição e alinhamento político ao presidente da República e ao governador do estado) dos mesmos influenciam na condução da política fiscal, o que ainda não foi realizado, nem para o caso catarinense, nem para o brasileiro.

Para essa análise foram utilizados dados em painel de 292 municípios de Santa Catarina, acompanhados de 2003 a 2014. Foram investigadas as despesas totais, os investimentos, as receitas tributárias, as operações de crédito e o saldo orçamentário dos municípios catarinenses. Durante o período analisado houve eleições para prefeitos e vereadores nos anos de 2004, 2008 e 2012.

O trabalho está dividido em cinco capítulos. O segundo capítulo consiste numa revisão da literatura acerca do oportunismo. O terceiro debruça-se sobre o caso brasileiro, mais especificamente sobre a realidade do federalismo orçamentário brasileiro e o seu sistema eleitoral e político. No quarto capítulo, há a especificação do modelo e da base de dados, além de também estarem expostos os resultados epíricos obtidos. No capítulo cinco são apresentadas as conclusões.

\section{REVISÃO DA LITERATURA}


http://dx.doi.org/10.5007/2175-8085.2018v21n1p01

A teoria dos ciclos político-econômicos (CPE) debruça-se sobre as consequências advindas da manipulação das políticas macroeconômicas, por parte dos governantes, com objetivos oportunistas. Nordhaus (1975) é um dos pioneiros na literatura dos CPE. Em seu estudo, The political business cycle de 1975, ele elaborou um modelo onde assume que a inflação e o desemprego são as únicas duas variáveis que os eleitores levam em conta quando estão a escolher em qual candidato votar, desta forma, se no momento $t$ (eleição) a economia se portou pior que as expectativas, no momento $t+1$, então os eleitores tenderão a votar no partido da oposição, e o contrário também ocorre, se a situação econômica for melhor que a esperada os eleitores tenderão a votar na continuidade.

Os modelos de Rogoff e Sibert (1988) e Rogoff (1990), ao contrário de Nordhaus (1975), alegam que os eleitores possuem expectativas racionais. Nesses modelos foi incluída uma nova variável que designa a competência do governante no poder. Os modelos de Rogoff e Sibert (1988) e Rogoff (1990) são denominados de modelos de Ciclos Político-Orçamentários (CPO), onde os governos utilizam as despesas e os impostos como instrumento para passarem uma imagem de competência e assim permanecerem no poder. Rogoff e Sibert (1988) elaboraram um modelo baseado em expectativas racionais, uma vez que para eles a hipótese de Nordhaus (1975) de os eleitores terem expectativas adaptativas e que podiam ser enganados constantemente, não é credível.

Para Rogoff e Sibert (1988) o ciclo dá-se porque há uma assimetria de informação entre o governante, que busca a reeleição, e os eleitores assumem que o governo tem mais informação que o eleitorado e, sendo assim, acaba por ter indicações de como a sua administração é avaliada. Com essas informações, o político no poder sabe quando deve sinalizar ao seu eleitorado que é um bom governante. Para atingir esse objetivo, o governo faz uso das políticas macroeconômicas e essa sinalização acaba por ser uma publicidade da competência do administrador público. Segundo Rogoff e Sibert (1988) os eleitores consideram que um político é competente quando este precisa de um nível inferior de receitas para oferecer um mesmo nível de bens e serviços à população. Como os eleitores observam a competência do político no poder com um desfasamento, então o político pode, por exemplo, reduzir impostos e financiar-se via emissão de dívida ou mesmo pela senhoriagem, ${ }^{1}$ uma vez que as consequências destas ações só serão observadas, pelo público, após um período

\footnotetext{
${ }^{1}$ Rogoff e Sibert (1988) salientam que a senhoriagem só pode ser utilizada por governos nacionais e não locais. Rev. Text. Econ., Florianópolis, v. 21 n. 1, p. 01 -24, dez/mar. 2018 ISSN 2175-8085
} 
temporal. Contudo, para os autores, a preocupação, do partido no governo, com o bem-estar da população ameniza os incentivos que ele tem para enganar a população.

Uma vez que o modelo proposto por Rogoff e Sibert (1988) considera a política fiscal (despesas e receitas públicas e saldo orçamentário), ele pode ser utilizado também para os governos regionais e locais, desde que os mesmos possuam competências sobre a política fiscal. A literatura dos CPOs encontrou na administração local campo bastante fértil. Para os governos subnacionais alemães podemos citar os trabalhos de Berger e Woitek (1997) e Seitz (1998) e para os municípios de Portugal há o trabalho de Veiga e Veiga (2007) que confirmou que os prefeitos portugueses manipulam os instrumentos de política econômica antes das eleições de forma a sinalizar uma maior competência, através da diminuição dos impostos, bem como aumento nas despesas, no ano das eleições (ou dois anos) o que acarreta um aumento do déficit orçamentário.

Aidt et al. (2010), por sua vez, realizaram um novo teste dos CPOs racionais para as localidades portuguesas e seus resultados empíricos indicam que, nos municípios portugueses, os políticos no poder que sejam oportunistas e aumentem o nível dos gastos no ano em que ocorrem as eleições, acabam por aumentar a diferença de votos em comparação ao seu principal adversário. Também foi percebido que há uma relação inversa entre o nível de manipulação fiscal e a margem de vitória.

No trabalho de Drazen e Eslava (2010), que analisou os municípios colombianos, foi considerado que os eleitores racionais não escolhem os seus candidatos com base no passado, mas sim nas políticas que os possíveis governantes venham a implementar. Por outro lado, os cidadãos deveriam perceber a manipulação do governo na política orçamentário, entretanto eles não o fazem.

Para o caso brasileiro há o trabalho de Nakaguma e Bender (2006) e Lautenschlage (aceito para publicação), para os estados, de Sakurai (2009) para os municípios de São Paulo e Sakurai e Menezes - Filho (2011) realizaram um estudo sobre a existência de ciclos de oportunismo ao nível dos municípios brasileiros. Eles encontraram evidências de ciclos eleitorais, chegando a conclusões similares às de Veiga e Veiga (2007) e Drazen e Eslava (2010). Seus resultados evidenciaram a existência de uma redução nos tributos e aumento nas despesas no ano em que se realizaram as eleições locais. Ainda sobre as receitas, Binet e Pentecôte (2004) e Foremmy e Riedel (2014) também evidenciaram reduções nos tributos nos anos com eleições nos municípios franceses e alemães, respectivamente. 
http://dx.doi.org/10.5007/2175-8085.2018v21n1p01

Esse comportamento oportunista foi estudados também ao nível das nações, por Vergne (2006), Andrikopoulos et al. (2006), Potrafke (2012), Katsimi e Sarantides (2012), Ehrhart (2013), Morozumi, Veiga e Veiga (2014). Para os governos estaduais pode-se citar os trabalhos de Blais e Nadeau (1992), Berger e Woitck (1997), Seitz (1998), Kneebone e Mckenzie (2001), Akhmedov e Zhuravskaya (2004), Tellier (2006), Nakaguma e Bender (2006) e Lautenschlage (aceito para publicação)

Rogoff (1990) percebeu que há, geralmente, uma alteração na composição dos gastos governamentais, em anos com eleições, ou seja, há uma preferência por despesas que tenham uma maior e imediata visibilidade. Ele constatou que há uma alteração na composição das despesas e nos investimentos públicos no ano pré-eleitoral. Os investimentos em capital são reduzidos e os gastos correntes são aumentados, isso ocorre porque os investimentos possuem um período de maturação superior o que faz com que os resultados dos mesmos só apareçam após um período de tempo. Por outro lado, os gastos correntes são percebidos pela população muito rapidamente, por isso são utilizados no ano pré-eleitoral. Um jardim novo na praça pode passar uma imagem ao eleitor de competência do político no poder. Sakurai e Menezes Filho (2011) evidenciou esse fenômeno nos municípios brasileiros.

Diferentemente de Rogoff (1990) e Sakurai e Menezes - Filho (2011), Nakaguma e Bender (2006) e Lautenschlage (aceito para publicação) evidenciaram, que nos estados brasileiros, em anos eleitorais, há um incremento nas despesas de investimentos que possuem maior visibilidade por parte do eleitorado. O mesmo fenômeno também foi evidenciado por Veiga e Veiga (2007) nos municípios portugueses. Drazen e Eslava (2010) evidenciaram que há um aumento em determinados tipos de gastos e diminuição em outros. Eles mostraram que há determinados tipos de despesas que são preferidas pelos políticos colombianos. Entre elas os autores citaram gastos com infraestrutura, também verificaram que as transferências, os pagamentos dos juros e a contratação de funcionários temporários são alterados. Por fim, constataram que há uma penalização por parte do eleitorado, quando ocorrem déficits préeleitorais. Eles constataram, também, que os eleitores penalizam os partidos no poder que incorrem em grande déficits antes das eleições, mas recompensam-nos pelos gastos com maior visibilidade. Por fim, eles concluíram que a probabilidade de reeleição aumenta quando o governante aumenta os gastos em bens que os eleitores preferem. 
http://dx.doi.org/10.5007/2175-8085.2018v21n1p01

\section{CASO BRASILEIRO}

O Brasil, conforme está contido na Constituição Federal, é uma República Federativa, constituída na forma de uma união indissolúvel dos Estados, do Distrito Federal e dos Municípios, os quais possuem competências sobre as despesas e receitas públicas, também determinados pela Carta Magna de 1988. Essa divisão de competências sobre a política físcal é comumente denominada de federalismo fiscal.

No Brasil todos os cargos políticos têm duração fixa de quatro anos, com isso, há eleições de dois em dois anos, intercalando as eleições nacionais e estaduais com as municipais. $\mathrm{O}$ primeiro turno de todas as eleições no Brasil ocorrem no primeiro domingo do mês de outubro, e o segundo, quando necessário, não possui uma data fixa, mas deve ocorrer somente após 10 dias a decorrer da realização da primeira.

\subsection{Federalismo fiscal}

Contudo, mesmo assim, não houve cisão, especialmente por que, segundo Giambiage e Além (2008), há uma língua única e uma certa homogeneidade cultural e religiosa, bem como por não existirem organismos pró separatismo, como na Irlanda do Norte e Espanha (com exceção de alguns movimentos pontuais como os realizados no final do século XIX no Estado do Rio Grande do Sul e em 1932 em São Paulo). Entretanto, esses confrontos usaram a separação como moeda de troca para que suas reivindicações fossem atendidas pelo Governo Central Brasileiro, que no primeiro caso ainda era a monarquia e no segundo era o Governo de Getúlio Vargas. Os municípios brasileiros têm um expressivo poder de influência sobre o Congresso Nacional, especialmente sobre a Câmara dos Deputados, uma vez que os administradores locais são os principais angariadores de votos nas eleições legislativas.

No caso do Brasil, pelo seu extenso e irregular território, convive com desigualdades socioeconômicas e o mesmo ocorre com o federalismo fiscal. Arretche (2004) argumenta que desde a Proclamação da República em 15 de novembro de 1889 até a atualidade, foi adotado, no Brasil, um regime em que há a separação das fontes tributárias, ou seja, cada esfera governativa tem competências exclusivas sobre determinados impostos. Segundo Serra e Afonso (1999), durante a chamada República Velha (1891-1930) a produção de café para exportação era a principal atividade econômica existente no Brasil. Nesse período, tanto no 
http://dx.doi.org/10.5007/2175-8085.2018v21n1p01

Brasil quanto no resto do mundo o Estado era reduzido. Isso mudou com a crise de 1929. Em 1930 Getúlio Vargas ascende ao poder após a Revolução de 30. Em seu Governo, ou Estado Novo, que vai até 1946, houve uma centralização de poderes por parte da União. Nesse período ocorreu um aumento do peso do setor público na economia, como no resto do mundo. Durante o Estado Novo, o Estado fortaleceu o mercado interno e deu início ao processo de industrialização do País. Em 1946, já com outro governo, ocorreu uma descentralização orçamentário. Durante a década de 1950 a União manteve sua participação na despesa total em cerca de $50 \%$.

Após o período democrático veio o Golpe Militar em 1964 que culminou com um período de Ditadura Militar (1964-1985). Segundo Resende (1995) nesse espaço de tempo houve uma concentração financeira nas mão do Governo Federal, sendo que durante esse período os prefeitos e governadores exerceram pressão para a descentralização, mas foi somente em 1982 é que essas duas esferas governamentais retomaram sua autonomia política, enquanto ao nível federal só em 1989 é que voltou a haver eleições presidenciais democráticas. Para Rezende (1995) e Serra e Afonso (1999) com a Constituição de 1988 a União continua a deter grande parte dos impostos em sua jurisdição, mas transfere grande parte desses recursos para os Estados e os municípios. Com isso, muitas prefeituras têm nessas transferências a principal fonte de receita. Outra situação que surge é que todos os municípios tentarão obter o maior montante possível. Para Arretche (2004) quando os governos estaduais e locais têm autonomia política e fiscal, eles têm liberdade de terem suas próprias políticas, não dependendo da União.

\subsection{Lei de responsabilidade fiscal}

A Lei de Responsabilidade Fiscal (LRF) (Lei Complementar $n^{\circ} 101 / 00$ ) representa um marco na história das finanças públicas brasileiras e não pode deixar de ser levada em consideração quando se trabalha com finanças públicas e política fiscal. A LRF impõem responsabilidades sobre a gestão orçamentário dos governos. Segundo Giambiage e Além (2008), a LRF brasileira foi baseada no Fiscal Responsibility Act, do governo neozelandês, que após realizar um programa de estabilização rigoroso, quis assegurar, através de uma lei, a manutenção do esforço de estabilização. Ela também estabelece limites para os gastos públicos e para o endividamento, além de determinar qual o porcentagem que deve ser gasto 
http://dx.doi.org/10.5007/2175-8085.2018v21n1p01

em educação, saúde e pessoal. As despesas públicas dos três entes federativos são determinadas por meio dos orçamentos, os quais devem ser transparentes, não só na sua elaboração, como na sua execução ${ }^{2}$.

No Brasil, os governantes possuem, segundo a Constituição Federal, uma relativa liberdade sobre as despesas públicas, contudo é exigido que todas as despesas estejam previstas no Orçamento Plurianual, na Lei de Diretrizes Orçamentárias e no Orçamento Anual. Entretanto, os municípios brasileiros são obrigados, segundo a Constituição, a manter, programas de educação infantil e de ensino fundamental bem como prestar serviços de atendimento à saúde, ambos com cooperação técnica e financeira do Governo Federal e Estadual. Também devem promover, quando couber, adequado ordenamento territorial e promover a proteção do património histórico e cultural local, sob fiscalização federal e estadual.

De acordo com a LRF, os municípios brasileiros possuem limites constitucionais sobre grande parte de suas despesas. Um exemplo disso é o fato de as despesas totais com pessoal, podem representar até $60 \%$ da receita corrente líquida. Sendo que, desse montante, há um limite de 6\% para o Poder Judiciário, 49\% para o Poder Executivo. Com relação ao Poder Legislativo, os limites variam de acordo com o número de habitantes, indo de $7 \%$ para Municípios com até 100.000 habitantes até 3,5\% para Municípios com mais de 8.000.001 de habitantes. A Câmara dos Vereadores (Poder Legislativo Local) só pode utilizar 70\% de sua receita com gastos em pessoal, incluindo os subsídios dos vereadores.

\section{TRABALHO EMPÍRICO}

Nessa seção é descrita a base de dados (Tabela 1) utilizada no exercício empírico, assim como o modelo e o método econométrico utilizado. Por fim, são expostos (Tabela 2) e analisados os resultados estimados.

2 Vicente, Benito e Bastida (2013) evidenciaram que nos municípios espanhóis, o grau de transparência das prefeituras inibe alterações oportunistas em anos eleitorais Akhmedov e Zhuravskaya (2004) chegaram à conclusões similares ao investigarem os governos regionais russos. Para o caso brasileiro há os trabalhos de Nakaguma e Bender (2006), Giuberti (2005), Gadelha (2012), Vasconcelos et al. (2013) e Lautenschlage (aceito para publicação) que focam no impacto da Lei de Responsabilidade sobre a condução da política fiscal nas três esferas de governo no Brasil. 


\subsection{Fontes de dados e estatísticas descritivas}

Para a análise da existência, ou não, de CPOs nos municípios do Estado de Santa Catarina, faz-se uso de dados obtidos junto de diversas fontes. Os dados sobre as contas públicas foram retirados do Ministério da Fazenda. As informações sobre os traços pessoais dos prefeitos e dos resultados eleitorais foram obtidas junto à Justiça Eleitoral Brasileira, nomeadamente o Tribunal Superior Eleitoral. Já os dados sobre a demografia e nível de produto dos municípios catarinenses foram conseguidos nas bases do Instituto Brasileiro de Geografia e Estatística (IBGE) e do Atlas Brasil ${ }^{3}$.

Tabela 1: Estatísticas descritivas

\begin{tabular}{|c|c|c|c|c|c|}
\hline VARIÁVEIS & $\begin{array}{l}(1) \\
\mathrm{N}\end{array}$ & $\begin{array}{l}(2) \\
\text { Média }\end{array}$ & $\begin{array}{c}\text { (3) } \\
\text { Desvio Padrão }\end{array}$ & $\begin{array}{c}(4) \\
\text { Mínimo }\end{array}$ & $\begin{array}{c}\text { (5) } \\
\text { Máximo }\end{array}$ \\
\hline Eleição & 2.794 & 0,271 & 0,445 & 0 & 1 \\
\hline ApósEleição & 2.794 & 0,234 & 0,423 & 0 & 1 \\
\hline Despesa & 2.794 & 2.906 & 2.105 & 789,6 & 88.487 \\
\hline Investimento & 2.794 & 425,3 & 409,3 & 0 & 6.093 \\
\hline Pessoal & 2.794 & 1.246 & 923,2 & 366,7 & 40.778 \\
\hline Tributos & 2.794 & 218,2 & 219,1 & 25,17 & 3.689 \\
\hline OCredito & 2.589 & 37,59 & 83,09 & 0 & 1.711 \\
\hline Saldo & 2.794 & 115,3 & 1.600 & -79.016 & 24.529 \\
\hline 1PIB & 2.784 & 25.104 & 11.970 & 7.268 & 179.428 \\
\hline Crescimento & 2.784 & 955,6 & 5.245 & -81.642 & 99.513 \\
\hline PES65 & 2.794 & 0,0670 & 0,0178 & 0,0317 & 0,136 \\
\hline Urbano & 2.794 & 0,538 & 0,251 & 0,0980 & 1 \\
\hline Analfabetos & 2.794 & 0,0843 & 0,0378 & 0,00910 & 0,229 \\
\hline Esquerda & 2.794 & 0,112 & 0,315 & 0 & 1 \\
\hline Feminino & 2.794 & 0,0426 & 0,202 & 0 & 1 \\
\hline Superior & 2.794 & 0,393 & 0,489 & 0 & 1 \\
\hline Reeleito & 2.794 & 0,200 & 0,400 & 0 & 1 \\
\hline Pres & 2.794 & 0,0941 & 0,292 & 0 & 1 \\
\hline Gov & 2.794 & 0,313 & 0,464 & 0 & 1 \\
\hline Ano & 2.794 & 2.008 & 3,342 & 2.003 & 2.014 \\
\hline Municípios & 292 & 292 & 292 & 292 & 292 \\
\hline
\end{tabular}

Para as análise foram utilizados dados de 292 municípios catarinenses observados entre os anos de 2003 e 2014, sendo que nesse período foram realizadas eleições locais nos anos de 2004, 2008 e 2012. A tabela 1 apresenta as estatísticas descritivas das variáveis utilizadas na análise.

\footnotetext{
${ }^{3}$ http://atlasbrasil.org.br/2013/

Rev. Text. Econ., Florianópolis, v. 21 n. 1, p. 01 - 24, dez/mar. 2018 ISSN 2175-8085
} 


\subsection{Descrição do modelo empírico e da base de dados}

Para testar a existência de ciclos político-orçamentários nos municípios do Estado de Santa Catarina foi implementado o seguinte modelo:

$$
\begin{array}{r}
y_{i t}=\sum_{j=1}^{p} \alpha_{j} y_{i, t-j}+X^{\prime}{ }_{i, t} \beta_{1}+M^{\prime}{ }_{i, t} \beta_{2}+P^{\prime}{ }_{i, t} \beta_{3}+O^{\prime}{ }_{i, t} \beta_{4}+\gamma_{i}+\varepsilon_{i t} \quad i=292, \ldots, N \quad t \\
=1, \ldots, 11
\end{array}
$$

No modelo acima a variável dependente $(y)$ será preenchida por seis variáveis fiscais do município $i$ no ano $t$-1, em termos per capita, expressas em reais a preços constantes de 31 de dezembro de 2016 ${ }^{4}$. Utiliza-se além das despesas totais (Despesa ${ }_{i t}$ ), as despesas com investimento (Investimento ${ }_{i t}$ ) e com pessoal (Pessoal ${ }_{i t}$ ), porque ambas são as principais componentes, respectivamente das despesas de capital e correntes, e assim, é possível realizar uma investigação sobre o fenómeno descrito por Rogoff (1990), no qual, as manipulações oportunistas, ocorrem na composição da despesas e não no montante total dos dispêndios públicos.

As receitas tributária (Tributos ${ }_{i t}$ ) e com operações de crédito (OCredito it) foram escolhidas pois são as que possuem maior grau de discricionariedade por parte dos prefeitos. Como o federalismo fiscal brasileiro apresenta uma concentração elevada de recursos nas esferas federal e estadual, as transferências possuem elevado peso no montante total das receitas e como as mesmas não são determinadas pelos governos locais, ou seja, são exógenas aos prefeitos, é mais prudente analisar essas duas componentes que estão sobre competência dos chefes do poder executivo local. Por fim, estuda-se o comportamento do saldo orçamentário $\left(\right.$ Saldo $\left._{i t}\right)$, que representa a diferença entre as receitas totais e as despesas totais dos municípios catarinenses.

$y_{i, t-j}$ representa a variável dependente defasada um período, o que torno o modelo (1) num modelo com dados em painel dinâmico não balanceado, dado que não há observações de todos os municípios para todos os anos.

No vetor $O^{\prime}{ }_{i, t}$ estão contidas variáveis que testam para o oportunismo.

- Eleicão $o_{i t}$ é uma variável binária que assume o valor um quando é ano de eleições municipais e o valor zero caso contrário;

\footnotetext{
${ }^{4}$ IGP-DI da Fundação Getúlio Vargas.

Rev. Text. Econ., Florianópolis, v. 21 n. 1, p. 01 - 24, dez/mar. 2018 ISSN 2175-8085
} 
- ApósEleição é uma variável binária que assume o valor um quando é o ano subsequente aos sufrágios locais e o valor zero caso contrário;

Essas duas variáveis é que capturam possíveis manipulações pré-eleitorais. Um ciclo político-orçamentário característico descrito por Rogoff e Sibert (1988) consiste numa elevação (diminuição) das despesas (receitas e saldo) nos anos com eleições, e uma diminuição (elevação) no ano subsequente. Isso ocorre porque a manipulação pré-eleitoral, terá de ser corrigida logo após a eleição. Entretanto, uma elevação nas despesas e redução nas receitas e no saldo nos anos eleitorais, já pode ser considerado comportamento oportunista, contudo, não gera um ciclo.

$X_{i, t}^{\prime}$, por sua vez, representa um vetor de variáveis explicativas que controlam para o nível de atividade econômica do município:

- $\quad l P I B_{i t}$ representa o montante, em reais, do produto interno bruto (PIB) per capita, do município $i$ no ano $t-1^{5}$, a preços constantes de 31 de dezembro de 2016;

- Crescimento ${ }_{i t}$ representa a variação do produto interno bruto do município $i$ entre os anos $t$ e $t-1$.

Ao se utilizarem essas variáveis controla-se para diferenças no desenvolvimento econômico dos diferentes municípios catarinenses, o que pode condicionar os níveis de despesa e receita pública.

$M^{\prime}{ }_{i, t}$, por sua vez, representa um vetor de variáveis explicativas que expressam as características demográficas dos municípios de Santa Catarina:

- $U_{r b a n o}$ é uma variável que mostra a parcela de população urbana no município $i$ no ano $t$;

- PES65 ${ }_{i t}$ é uma variável que mostra a porcentagem de população com mais de 65 anos de idade no município $i$ no ano $t ;^{6}$

- Analfabetos $s_{i}$ é uma variável que mostra o percentual de população analfabeta no município $i$ no ano $t$;

Essas variáveis são importantes de serem utilizadas, porque a estrutura demográfica possui influência sobre as despesas e as receitas públicas, por exemplo, um município com maior grau porcentagem de população a residir na zona urbana, apresenta uma estrutura de

\footnotetext{
${ }^{5}$ Utiliza-se o valor defasado do PIB, para evitar problemas de endogeneidade

${ }^{6}$ Foram estimados modelos com a variável PES15 $5_{i t}$ (percentagem da população com menos de 15 anos de idade do estado $i$ no período $t$ ) que controlava para a estrutura etária da população, mas o teste Fator de Inflação da Variância (Variance Inflation Factor - VIF) indicou a presença de multicolinearidade, o que levou a exclusão de tal variável.

Rev. Text. Econ., Florianópolis, v. 21 n. 1, p. 01 -24, dez/mar. 2018 ISSN 2175-8085
} 
despesas diferente das localidades mais rurais, o mesmo vale com a receita tributária, como o IPTU (Imposto Predial e Territorial Urbano) que é uma das principais fontes de recursos dos municípios. A parcela de idosos também influencia nas despesas públicas, especialmente sobre a sua composição. Já o percentual de analfabetos funciona como uma aproximação (proxy) do inverso do capital humano no município.

$\mathrm{O}$ vetor $P^{\prime}{ }_{i, t}$ agrupa as variáveis com os traços pessoais dos prefeitos:

- Feminino ${ }_{i t}$ é uma variável binária que assume o valor um quando se trata de um prefeito do sexo feminino e o valor zero caso contrário;

- Esquerda $a_{i t}$ é uma variável binária que assume o valor um quando se trata de um prefeito pertencente a um partido de esquerda e o valor zero caso contrário ${ }^{7}$;

- Reeleito ${ }_{i t}$ é uma variável binária que assume o valor um quando se trata de um município no qual o prefeito está em segundo mandato consecutivo e impedido de buscar a reeleição e o valor zero caso contrário.

- Superior $_{i t}$ é uma variável binária que assume o valor um quando se trata de um prefeito com no mínimo o ensino superior completo e o valor zero caso contrário;

- Pres $_{i t}$ é uma variável binária que assume o valor um quando se trata de um prefeito pertencente ao mesmo partido do Presidente da República e o valor zero caso contrário;

- Gov $_{i t}$ é uma variável binária que assume o valor um quando se trata de um prefeito pertencente ao mesmo partido do Governador do Estado ou do Distrito Federal e o valor zero caso contrário

Nos últimos anos a literatura da economia política tem se debruçado sobre a influência dos traços pessoais dos políticos sobre a condução da política fiscal. A ideologia é a característica que mais tem sido investigada (Hibbs, 1977; Alesina 1987; Veiga e Veiga, 2007; Sakurai, 2009; Drazen e Eslava, 2010; Aidt et al., 2010, Sakurai e Menezes - Filho, 2011, Klein e Sakurai, 2015 e Chortareas et al. 2016), entretanto há outras que têm vindo a atrair atenções dos estudiosos, como o gênero (Chattopadhyay e Duflo, 2004; Jacobsen, 2006; Park, 2014; e Ferreira e Gyourko, 2014), os anos de estudo (Corneo e Grüner, 2002; Alesina e La Ferrara, 2005; Jacobsen, 2006; Alesina e Giuliano, 2009; Hayo e Neumeier, 2012; Hayo e Neumeier 2014; e Martínez-Bravo, 2017), o alinhamento político (Ferreira e Bugarin, 2007;

7 A classificação proposta pode Zucco (2011) foi utilizada para identificar os partidos de acordo com sua ideologia.

Rev. Text. Econ., Florianópolis, v. 21 n. 1, p. 01 - 24, dez/mar. 2018 ISSN 2175-8085 
Aidt et al. 2010; Sakurai e Menezes-Filho, 2011; Brollo e Nannicini, 2012; e Chortareas et al. 2016) e a limitação de mandatos (Besley e Case, 1995; Nakaguma e Bender, 2006; Klein e Sakurai, 2015; Veiga e Veiga, 2016).

Ao utilizar essas variáveis como controle, consegue-se isolar a influência desses traços pessoais sobre a condução da política fiscal e por conta do elevado número de traços, esse trabalho inova, tanto ao nível da literatura brasileira, como mundial. Por fim, $\alpha_{j}, \beta_{1}, \beta_{2}, \beta_{3} \mathrm{e}$ $\beta_{4}$ representam vetores de parâmetros a estimar, $\gamma_{i}$ são os efeitos individuais e $\varepsilon_{i t}$ é o termo de erro.

\subsection{Estratégia econométrica}

Considerando o modelo 1, nota-se que ao acrescentar a variável dependente defasada, como uma variável explicativa, obtém-se um modelo de dados em painel dinâmico. Ao fazer isso, o valor passado da variável dependente ajuda agora a explicar o comportamento da variável dependente no presente. Quando se usam modelos dinâmicos surgem problemas tanto nas estimações por OLS, quanto por efeitos fixos e efeitos aleatórios, uma vez que há correlação entre o efeito fixo $\left(\gamma_{i}\right)$ e a variável dependente defasada, mesmo que $\varepsilon_{i t}$ não esteja autocorrelacionado (Greene, 2003).

Para resolver os problemas com a variável dependente defasada como variável explicativa, Arellano e Bond (1991) desenvolveram um estimador dinâmico para dados em painel, que além de resolver esses problemas ainda é indicado, principalmente, para casos onde o horizonte temporal $(t)$ é pequeno e o número de indivíduos observados $(i)$ é elevado, o que é o caso deste trabalho onde $t=11$ e $i=292$. Arellano e Bond (1991) propuseram que todos os regressores sejam transformados retirando a primeira diferença e somente então seja aplicado o GMM (Método dos momentos generalizado). Ao realizar tal procedimento os efeitos individuais $\gamma_{i}$ são removidos.

Arellano e Bover (1995) e Blundell e Bond (1998), por sua vez, assumiram uma hipótese adicional a de Arrelano e Bond (1991). Eles assumem que as primeiras diferenças das variáveis instrumentais são, também, não correlacionadas com os efeitos individuais $\gamma_{i}$. Isso é feito para aumentar o número de instrumentos a serem introduzidos, bem como a eficiência do estimador. Com isso, obtém-se um sistema com duas equações (Sistema GMM), que é a escolha mais utilizada nos trabalhos empíricos contidos na literatura dos CPO. 
http://dx.doi.org/10.5007/2175-8085.2018v21n1p01

Nas estimações por SGMM de duas etapas (two-step) temos a união da retirada da primeira diferença mais a equação em níveis. Quando o two-step é utilizado em detrimento do one-step (uma etapa) é necessário corrigir os erros padrão, já que se não o fizer os erros padrão serão tendenciosos para baixo. Para resolver esse problema, Windmeijer (2000) propôs uma estimativa para os erros padrão para uma estimação em duas etapas e para amostras finitas, que não os torna tendenciosos e permite, também, que haja, sobre a matriz dos instrumentos, um controlo mais eficiente.

O teste de Hansen testa a exogeneidade dos instrumentos, sob a hipótese nula, de que os instrumentos são exógenos, esta estatística de teste segue a distribuição $\chi_{L-K}^{2}$, onde $L-K$ é igual ao número de restrições sobre-identificadas. Os testes de autocorrelação são aplicados para os erros após a diferenciação. No caso dos testes de autocorrelação de Arellano e Bond a hipótese nula é de que não haja autocorrelação. Em estimações que utilizam o método Arellano e Bond (1991) espera-se que haja autocorrelação de primeira ordem AR(1), contudo não deve haver autocorrelação de segunda ordem AR(2). Uma vez que o GMM é o método mais adequado para o painel dinâmico utilizado no trabalho, as estimações subsequentes foram realizadas com recurso a este método.

\subsection{Resultados empíricos}

Para analisar a existência de CPOs ao nível das despesas totais, investimentos, despesas com pessoal, receitas tributárias, operações de crédito e saldo orçamentário, nos municípios catarinenses, foram realizadas seis estimações conforme a Tabela 2. Na coluna 1 temos como variável dependente a estimação com o total das despesas totais (Despesa).

Os resultados contidos na coluna 1 da Tabela 2, indicam que não há manipulações oportunistas nas despesas totais nos municípios catarinenses nos moldes propostos por Rogoff e Sibert (1988), com aumentos nas mesmas nos anos com eleições. Esse resultado vai contra as conclusões de Sakurai e Menezes-Filho (2011) para os municípios brasileiros e de Nakaguma e Bender (2006) e Lautenschlage (aceito para publicação) para os estados do Brasil, uma vez que esses trabalhos evidenciaram manipulações nessa componente fiscal no ano com votações. Esse resultado pode sugerir que os políticos catarinenses não se utilizam de artimanhas oportunistas para se reelegerem. Ainda sobre as despesas totais, os resultados contidos na coluna 1 da Tabela 2, indicam que há uma redução das mesmas no ano 
http://dx.doi.org/10.5007/2175-8085.2018v21n1p01

subsequente às eleições municipais (-151,6 reais por habitante) o que sugere a existência de uma correção fiscal, após as eleições.

Tabela 2: Ciclos Político-Orçamentais componentes fiscais

\begin{tabular}{|c|c|c|c|c|c|c|}
\hline Variáveis & $\begin{array}{c}(1) \\
\text { Despesa }\end{array}$ & $\begin{array}{c}(2) \\
\text { Investimento }\end{array}$ & $\begin{array}{c}(3) \\
\text { Pessoal }\end{array}$ & $\begin{array}{c}\text { (4) } \\
\text { Tributos }\end{array}$ & $\begin{array}{c}(5) \\
\text { OCredito } \\
\end{array}$ & $\begin{array}{c}(6) \\
\text { Saldo } \\
\end{array}$ \\
\hline Eleição & $\begin{array}{c}-27,97 \\
(-0,420)\end{array}$ & $\begin{array}{c}81,13 * * * \\
(5,030)\end{array}$ & $\begin{array}{l}-50,33 * \\
(-1,652)\end{array}$ & $\begin{array}{c}-13,05^{* * *} \\
(-3,070)\end{array}$ & $\begin{array}{c}26,43 * * * \\
(6,497)\end{array}$ & $\begin{array}{c}-46,41 \\
(-0,723)\end{array}$ \\
\hline ApósEleição & $\begin{array}{c}-115,6^{* *} \\
(-2,122)\end{array}$ & $\begin{array}{c}-95,95 * * * \\
(-6,744)\end{array}$ & $\begin{array}{c}7,828 \\
(0,267)\end{array}$ & $\begin{array}{c}-8,601 * * * \\
(-2,676)\end{array}$ & $\begin{array}{c}-1,534 \\
(-0,486)\end{array}$ & $\begin{array}{l}153,6 * * \\
(2,395)\end{array}$ \\
\hline IPIB & $\begin{array}{c}0,0414 * * * \\
(7,200)\end{array}$ & $\begin{array}{c}0,00748 * * * \\
(6,866)\end{array}$ & $\begin{array}{c}0,0171 * * * \\
(5,603)\end{array}$ & $\begin{array}{c}0,00182 * * \\
(2,244)\end{array}$ & $\begin{array}{c}0,00112 * \\
(1,721)\end{array}$ & $\begin{array}{c}0,00769^{* *} \\
(2,494)\end{array}$ \\
\hline Crescimento & $\begin{array}{c}0,0243 * * * \\
(6,184)\end{array}$ & $\begin{array}{c}0,00302 * * \\
(2,272)\end{array}$ & $\begin{array}{c}0,0108 * * * \\
(6,111)\end{array}$ & $\begin{array}{c}0,00243 * * \\
(2,092)\end{array}$ & $\begin{array}{c}0,000470 \\
(1,268)\end{array}$ & $\begin{array}{c}0,00404^{* *} \\
(2,416)\end{array}$ \\
\hline PES65 & $\begin{array}{c}19.345 * * * \\
(5,537)\end{array}$ & $\begin{array}{c}3.016 * * * \\
(4,184)\end{array}$ & $\begin{array}{c}9.583 * * * \\
(7,160)\end{array}$ & $\begin{array}{c}260,5 \\
(1,334)\end{array}$ & $\begin{array}{c}296,3 * * \\
(2,185)\end{array}$ & $\begin{array}{c}3.267 * * * \\
(6,338)\end{array}$ \\
\hline Urbano & $\begin{array}{c}-1.696 * * * \\
(-6,600)\end{array}$ & $\begin{array}{c}-313,4 * * * \\
(-5,728)\end{array}$ & $\begin{array}{c}-440,1 * * * \\
(-3,979)\end{array}$ & $\begin{array}{l}119,3^{*} \\
(1,765)\end{array}$ & $\begin{array}{c}-32,04 * * * \\
(-3,011)\end{array}$ & $\begin{array}{l}-53,40 \\
(-1,112)\end{array}$ \\
\hline Analfabetos & $\begin{array}{c}4.540 * * \\
(2,279)\end{array}$ & $\begin{array}{l}664,2^{*} \\
(1,783)\end{array}$ & $\begin{array}{c}2.267 * * * \\
(3,235)\end{array}$ & $\begin{array}{c}10,70 \\
(0,103)\end{array}$ & $\begin{array}{c}47,81 \\
(0,582)\end{array}$ & $\begin{array}{c}-69,25 \\
(-0,115)\end{array}$ \\
\hline Esquerda & $\begin{array}{c}-274,2 \\
(-0,834)\end{array}$ & $\begin{array}{c}-53,23 \\
(-0,880)\end{array}$ & $\begin{array}{c}-100,6 \\
(-0,781)\end{array}$ & $\begin{array}{c}7,312 \\
(0,206)\end{array}$ & $\begin{array}{l}-50,71 * \\
(-1,775)\end{array}$ & $\begin{array}{c}-99,44 \\
(-0,337)\end{array}$ \\
\hline Feminino & $\begin{array}{c}573,1 * * * \\
(2,719)\end{array}$ & $\begin{array}{l}73,00^{*} \\
(1,799)\end{array}$ & $\begin{array}{c}282,7 * * * \\
(2,878)\end{array}$ & $\begin{array}{c}-3,279 \\
(-0,158)\end{array}$ & $\begin{array}{c}-0,791 \\
(-0,0800)\end{array}$ & $\begin{array}{c}181,8 * * * \\
(2,674)\end{array}$ \\
\hline Superior & $\begin{array}{c}330,9 * * * \\
(3,727)\end{array}$ & $\begin{array}{c}99,91 * * * \\
(3,288)\end{array}$ & $\begin{array}{c}110,3 * * * \\
(3,283)\end{array}$ & $\begin{array}{c}5,531 \\
(0,697)\end{array}$ & $\begin{array}{l}12,46^{*} \\
(1,965)\end{array}$ & $\begin{array}{l}88,43^{*} \\
(1,839)\end{array}$ \\
\hline Reeleito & $\begin{array}{c}33,95 \\
(0,511)\end{array}$ & $\begin{array}{l}37,30^{*} \\
(1,660)\end{array}$ & $\begin{array}{c}-5,846 \\
(-0,245)\end{array}$ & $\begin{array}{l}-12,57^{*} \\
(-1,741)\end{array}$ & $\begin{array}{c}-2,311 \\
(-0,585)\end{array}$ & $\begin{array}{c}-6,483 \\
(-0,200)\end{array}$ \\
\hline Pres & $\begin{array}{c}224,1 \\
(0,595)\end{array}$ & $\begin{array}{c}32,57 \\
(0,450)\end{array}$ & $\begin{array}{c}105,6 \\
(0,730)\end{array}$ & $\begin{array}{c}4,931 \\
(0,122)\end{array}$ & $\begin{array}{c}59,06 \\
(1,632)\end{array}$ & $\begin{array}{c}236,8 \\
(0,595)\end{array}$ \\
\hline Gov & $\begin{array}{c}-61,84 \\
(-0,577)\end{array}$ & $\begin{array}{c}66,43 * * * \\
(3,080)\end{array}$ & $\begin{array}{l}-105,4 * \\
(-1,920)\end{array}$ & $\begin{array}{c}-6,041 \\
(-1,261)\end{array}$ & $\begin{array}{c}-1,775 \\
(-0,507)\end{array}$ & $\begin{array}{c}26,36 \\
(0,345)\end{array}$ \\
\hline$Y_{t-1}$ & $\begin{array}{c}0,108 \\
(1,256)\end{array}$ & $\begin{array}{c}0,264 * * * \\
(3,993)\end{array}$ & $\begin{array}{c}0,105 \\
(1,130)\end{array}$ & $\begin{array}{c}0,634 * * * \\
(2,890)\end{array}$ & $\begin{array}{l}-0,0296 \\
(-0,982)\end{array}$ & $\begin{array}{c}0,00885 \\
(1,335)\end{array}$ \\
\hline Constante & $\begin{array}{l}673,2 * \\
(1,932)\end{array}$ & $\begin{array}{c}-30,40 \\
(-0,430)\end{array}$ & $\begin{array}{c}74,02 \\
(0,448)\end{array}$ & $\begin{array}{c}-35,67 \\
(-1,535)\end{array}$ & $\begin{array}{c}-9,617 \\
(-0,404)\end{array}$ & $\begin{array}{c}-350,9 * * * \\
(-2,916)\end{array}$ \\
\hline Observações & 2.777 & 2.777 & 2.777 & 2.777 & 2.553 & 2.777 \\
\hline Municípios & 292 & 292 & 292 & 292 & 292 & 292 \\
\hline F-teste & 12,85 & 104,7 & 61,50 & 2,505 & 40,70 & 137,2 \\
\hline Prob $>$ F & 0,000396 & 0 & 0 & 0,115 & $6,98 \mathrm{e}-10$ & 0 \\
\hline Hansenp & 0,162 & 0,201 & 0,163 & 0,410 & 0,418 & 0,374 \\
\hline AR $1 p$ & 0,297 & 0,000382 & 0,309 & 0,251 & 0,000102 & 0,267 \\
\hline AR2p & 0,437 & 0,683 & 0,452 & 0,489 & 0,129 & 0,454 \\
\hline
\end{tabular}

Notas: - Estatística t entre parênteses.- Níveis de significância $* 10 \%, * * 5 \% \mathrm{e} * * * 1 \%$. O F-teste representa o teste de Wald que possui como hipótese nula a combinação linear entre as variáveis explicativas Eleição e ApósEleição H0: $\beta$ Eleição - ApósEleição $=0$. Prob $>$ F indica o p-valor do teste de Wald. - O valor de Hansen é o p-valor. O Teste de Hansen testa a exogeneidade dos instrumentos, sob a hipótese nula, de que os instrumentos são exógenos, esta estatística do teste segue a distribuição $\chi_{\mathrm{L}-\mathrm{K}}^{2}$, onde $\mathrm{L}-\mathrm{K}$ é igual ao número de restrições sobreidentificadas.- Considerou-se que as variáveis $l P I B$, Crescimento, Esquerda, Feminino, Superior, Reeleito, Pres e Gov são pré-determinadas e desta forma foi aplicado GMM às mesmas, sendo que as lags variaram de 1 à 6. - Os defasamento da variável dependente variaram de 2 à 6.- AR1p e AR2p representam os p-valores dos testes para correlação serial de primeira ordem e segunda ordem nos resíduos da primeira diferença, assimptoticamente distribuídos como $\mathrm{N}(0,1)$ sobre a hipótese nula de haver correlação serial. 
Por outro lado, quando se foca na composição da despesa pública local, nota-se que há um incremento de, em média, 81,13 reais por habitante nas despesas com investimentos em anos com eleições municipais em comparação aos demais anos, tudo o resto igual. Esse resultado vai de encontro ao proposto por Rogoff (1990) o qual sustenta que o há migração para as despesas correntes em anos eleitorais e ao constatado por Sakurai e Menezes-Filho (2011) para os municípios brasileiros. Contudo, esse resultado está em linha com as evidências Nakaguma e Bender (2006) e Lautenschlage (aceito para publicação) para os estados brasileiros e de Veiga e Veiga (2007) e Drazen e Eslava (2010), para os municípios portugueses e colombianos, respectivamente. Outro ponto importante é que os investimentos apresentam uma redução no ano subsequente às eleições de, em média, 95,95 reais por habitante, ceteris paribus, o que indica a existência de ciclos político-orçamentários, uma vez que há elevação nessa componente no ano com eleições e redução no posterior.

As despesas com pessoal apresentam um comportamento interessante, há indícios (10\% de significância) de que as mesmas são reduzidas em, em média, 50,33 reais por habitante nos anos com eleições municipais, tudo o resto igual, o que contraria o senso comum, de que os políticos aumentam as despesas antes das eleições. Entretanto, é preciso salientar que a LRF apresenta limitadores para as despesas com pessoal no ano com pleitos, desta forma, assim como foi constatado por Giuberti (2005), Gadelha (2012) e Lautenschlage (aceito para publicação), a LRF tornou mais difícil as manipulações oportunistas nessa componente da despesa pública.

Migrando para o lado das receitas, nota-se ao analisar a coluna 4 da Tabela 2, que os recursos tributários diminuem, em média, 13,05 reais por habitante em anos com eleições locais quando comparados aos demais anos, tudo o resto igual. Esses resultados vão ao encontro do que foi proposto por Rogof e Sibert (1988) e constatado por Yoo (1998), Binet e Pentecôte (2004), Katsimi e Sarantides (2012), Ehrhart (2013), Foremmy e Riedel (2014) e Lautenschlage (2016) e indicam a existência de comportamento oportunista a arrecadação tributárias nos município do Estados de Santa Catarina. Isso ocorre porque há uma redução nessa arrecadação nos períodos que antecedem os sufrágios locais.

Nos anos em que são realizadas as eleições locais, observa-se, como sugerem os resultados expostos na coluna 5 da Tabela 2, que há uma elevação de, em média, 26,43 reais por habitante nas receitas advindas de operações de crédito, ceteris paribus. Esse resultado deve ser analisado em conjunto com os investimentos, dado que, segundo a LRF, as 
operações de crédito estão limitadas às despesas de capital. Desta forma, um aumento nas despesas de capital, que nesse exercício empírico estão representados pela sua principal componente, os investimentos, permitem que haja uma elevação nas operações de crédito. Posto isso, ao analisarmos as operações de crédito e investimento em simultâneo, percebe-se que ambas apresentam uma elevação nos anos com eleições, o que pode sugerir que para financiar as elevações nos investimentos, os prefeitos recorrem aos recursos de instituições de crédito, ao invés dos tributos, dado que a receita tributária é reduzida nos anos com votações. Em outras palavras, pode-se argumentar que o financiamento do oportunismo nos investimentos e nos tributos, recai sobre as operações de crédito, até porque o saldo não apresenta alteração, conforme os resultados expostos na coluna 6 da Tabela 2.

Ainda sobre o saldo orçamentário, os resultados contidos nas colunas 1 e 6 da Tabela 2 indicam que pelo fato de não haver incremento nas despesas totais, o saldo também não apresenta piora nos anos com eleições, tudo o resto igual. Já no ano subsequente às eleições, o saldo apresenta uma melhora, ele é elevado, em média, em 153,6 reais por habitante, ceteris paribus. Esse resultado indica, assim como a redução nas despesas totais, que há, no ano que segue os sufrágios locais, que no caso brasileiro coincide com o início do novo mandato, uma correção orçamentária.

Esses resultados das variáveis fiscais indicam que os investimentos, que não são objeto de limitações legais, são ainda manipulados em anos com eleições. Somado a essa realidade, há a elevação nas operações de crédito, que possivelmente, será quitada pelo próximo governante. Esses fenômenos têm a capacidade de gerarem ineficiências nas contas públicas e por conta disso, deveriam ser limitados.

O nível passado do produto interno bruto (PIB) dos municípios catarinenses apresenta influência sobre os níveis de despesas totais, investimentos, despesas com pessoal, receitas tributárias e saldo orçamentário. Os resultados expostos na Tabela 2 indicam, que um aumento de um real no produto interno bruto per capita no ano $t-1$ acarreta num aumento de, em média, 0,04 reais por habitante nas despesas totais, 0,007 reais per capita nos investimentos, 0,01 reais por habitante nas despesas com pessoal, 0,001 reais por habitante nos tributos arrecadados e 0,007 reais no saldo orçamentário per capita no ano $t$. O mesmo ocorre com a variação no produto, representado pela variável Crescimento $_{i t}$.

Os resultados mostram também que os municípios com maior população idosa, apresentam, ceteris paribus, maiores níveis médios de despesas totais por habitante $(+19,34$ 
http://dx.doi.org/10.5007/2175-8085.2018v21n1p01

reais por habitante para cada ponto percentual adicional na população com mais de 65 anos de idade), investimentos ( +3 reais por habitante), despesas com pessoal 9,6 reais por habitante, operações de crédito $(+296,3$ reais por habitante) e saldo orçamentário $(+3,3$ reais por habitante).

Já a parcela de população urbana afeta negativamente as despesas totais $(-1,7$ reais por habitante), os investimentos (-313,4 reais por habitante), as despesas com pessoal $(-440,1$ reais por habitante) e as receitas advindas de operações de crédito (-31,04 reais por habitante), ceteris paribus. Uma das possíveis explicações para esses resultados reside no fato dos municípios com maior parcela da população a viver nas cidades, despendem menos com obras públicas em geral, dado que já apresentam um estoque de capital significativo, o que explica o a relação inversa entre o grau de urbanização e os investimentos. Há indícios $(10 \%$ de significância) que de em municípios mais urbanizados há maior arrecadação de impostos, esse resultado era esperado, pelo fato de os principais tributos municipais, estarem ligados à propriedade predial e territorial urbana (IPTU) e impostos sobre serviços de qualquer natureza (ISSQN).

Os resultados indicam ainda, que a porcentagem da população analfabeta tem influência nas despesas totais e com pessoal. Para cada elevação em um ponto percentual na população analfabeta, acarreta num aumento de 4,5 reais por habitante nas despesas totais e 2,3 reais per capita nas despesas com pessoal, ceteris paribus. Esses resultados obtidos para as características demográficas dos municípios catarinenses indicam que tanto a parcela da população com mais de 65 anos de idade, como a urbana e analfabeta, têm influência sobre os níveis de despesa. A população idosa também influencia as receitas e o saldo orçamentário e a parcela a residir nas cidades têm influência sobre as receitas.

Ao migrar para os traços pessoais dos prefeitos de Santa Catarina, encontrou-se evidências de que o gênero, o nível de estudo e o alinhamento político ao governador d estado, impactam na condução da política fiscal. Os resultados indicam que os governantes locais do sexo feminino apresentam, em média, maiores níveis de despesas totais $(+573,1$ reais por habitante) e com pessoal ( $+282,7$ reais por habitante), além de possuírem melhores saldos orçamentários $(+181,8$ reais por habitante), quando comparadas aos seus congêneres do sexo masculino, tudo o resto igual.

O fato do governo municipal ser encabeçado por um prefeito com, no mínimo, o ensino superior completo, acarreta, no caso catarinense e tudo o resto igual, em maiores níveis 
http://dx.doi.org/10.5007/2175-8085.2018v21n1p01

de despesas totais $(+331$ reais por habitante), de investimentos $(+100$ reais por habitante) e despesas com pessoal ( $+110,3$ reais por habitante). A Influência do nível de estudo do prefeito sobre as despesas totais (coluna 1 da Tabela 2) está em linha com as evidências de Martinez (2017), para os distritos indonésios, mas divergem das de Jacobsen (2006) para os municípios noruegueses. Os municípios governados por prefeitos pertencentes ao partido do governador, investem, em média, mais que os não alinhados $(+66,43$ reais por habitante), tudo o resto igual.

As demais características dos prefeitos (ideologia de esquerda, limitação de mandato e alinhamento político ao presidente da República) não são estatisticamente significativas. Esse resultado não significativo da ideologia sobre a condução da política fiscal já era esperado, pois como Mainwaring (1999) argumenta, o sistema partidário brasileiro é muito frouxo, os políticos mudam de partido frequentemente, ou seja, não há fidelidade partidária. No entanto, Sakurai e Menezes-Filho (2011) e Klein e Sakurai (2015) evidenciaram uma relação entre ideologia e os níveis de despesas públicas.

Já os resultados expostos na Tabela 2 sobre a limitação de mandato estão em linha com os resultados de Klein (2010) para os municípios brasileiros, mas contradizem os resultados Besley e Case (1995) para os estados dos Estados Unidos, de Nakaguma e Bender (2006), para os estados brasileiros e de Klein e Sakurai (2015), cujas evidências indicam uma relação entre a limitação de mandatos e a política fiscal nos municípios brasileiros. Por fim, o fato do prefeito e do presidente da República serem do mesmo partido não influenciar na condução da política fiscal dos municípios de Santa Catarina, diverge das conclusões de Chortareas et al. (2016) para o alinhamento entre os governos locais gregos e o governo central.

\section{CONCLUSÕES}

Este trabalho tem como objetivo analisar a existência de CPOs nos municípios catarinenses. Para isso, foram estimadas algumas regressões para testar se há indícios da existência desses ciclos. Os resultados obtidos não sustentam a hipótese de elevações nas despesas nos anos com eleições e redução no seguinte, como descrito por Rogoff e Sibert (1988). Por outro lado, os resultados indicam a existência de CPOs nas despesas com investimento nos municípios catarinenses, uma vez que há elevação nos mesmos nos anos 
com eleições e queda no subsequente. Esse resultado que vai ao encontro do que foi proposto por Rogoff (1990), que os governantes manipulam a composição das despesas objetivando, com isso, passar aos eleitores que são políticos competente e assim conseguirem ter melhores resultados eleitorais. As despesas com pessoal, por sua vez, da mesma forma que as despesas totais, não parecem ter sido influenciadas pelo oportunismo.

Pelo lado da receita há uma redução nas receitas tributárias nos anos com eleições, o que indica um comportamento oportunista, nos moldes descritos por Rogoff e Sibert (1988). As operações de crédito, apresentam uma elevação, o que não deixa de ser classificado como oportunismo, dado que as mesmas serão pagas após as eleições se realizarem. O saldo orçamentário não apresentou alteração no ano com eleições. Contudo, há uma elevação no ano subsequente às eleições, indicando, conjuntamente com as reduções nas despesas totais e com investimento, que há uma consolidação fiscal após as votações nos municípios catarinenses. Esse exercício empírico encontrou evidências de que o nível do produto e as características dos municípios catarinenses, influenciam na condução da política físcal. $\mathrm{O}$ mesmo ocorre com o género, a formação superior e o alinhamento político do prefeito com o governador.

Esses resultados podem ser úteis para perceber como as finanças públicas são geridas em Santa Catarina o que pode ser uma mais valia aos órgãos de controlo da administração pública, para que os mesmos possam implementar mecanismos que inibam essas manipulações nos mecanismos de política fiscal, que não são benéficas à saúde financeira da administração local. Esse controle deveria focar nos investimentos, dado que a LRF, não versa sobre o mesmo e que de acordo com Sakurai e Menezes-Filho (2008) são mais bem recebidos pelos eleitores brasileiros, aumentando assim as chances de reeleição. A Lei de Responsabilidade Fiscal foi elaborada com o intuito de minorar a má administração dos recursos públicos, contudo, a mesma deve ser periodicamente complementada, para que se possa inibir esse problema.

Para trabalhos futuros seria interessante expandir a análise para a totalidade dos municípios brasileiros, bem como estudar se as características dos municípios e dos prefeitos, condicionam o oportunismo.

\section{REFERÊNCIAS BIBLIOGRÁFICAS}

Aidt, T.S.; Veiga, F. J.; Veiga. L. G. (2011). Election results and opportunistic policies: a new Rev. Text. Econ., Florianópolis, v. 21 n. 1, p. $01-24$, dez/mar. 2018 ISSN 2175-8085 
test of the rational political business cycle model. Public Choice, 148, 21-44.

Akhmedov, A.; Zhuravskaya, E. (2004). Opportunistic political cycles: test in a young democracy setting. Quarterly Journal of Economics, 119, 1301-1338.

Alesina, A. (1987). Macroeconomic policy in a two-party system as a repeated game. Quarterly Journal of Economics, 02, p. 651-78.

; La Ferrara, E. (2005). Ethnic diversity and economic performance. Journal of Economic Literature, 43(3), p. 762- 800.

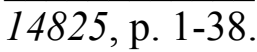

; Giuliano, P. (2009). Preferences for redistribution, NBER Working Paper

Andrikopoulos, A.; Loizides, I.; Prodromidis, K. (2006) Taxation and political business cycles in EU economies. Apllied Economics, 38, 1761-1774.

Arellano, M.; Bond, S. (1991). Some tests of specification for panel data: Monte Carlo evidence and an application to employment equations. The Review of Economic Studies, 58, 277-297.

Arellano, M.; Bover, O. (1995). Another look at the instrumental variable estimation of errorcomponent models. Journal of Econometrics, 68, 29-51.

Arretche, M.(2004). Federalismo e políticas sociais no brasil: problemas de coordenação e autonomia. São Paulo em Perspectiva, 18(2): 17-26.

Berger, H.; Woitek, U. (1997) Searching for Political Business Cycles in Germany. Public Choice, 91(2), 179-197.

Besley, T; CASE, A. (1995). Does electoral accountability affect economic policy choices? Evidence from gubernatorial term limits. The Quarterly Journal of Economics, 110(3), p. 769-798.

Binet, M. E., Pentecôte, J. S. (2004) Tax degression and the political budget cycle in French municipalities. Applied Economics Letters, 14(11), p. 905-908.

Blais, A.; Nadeau, R. (1992). The electoral budget cycle. Public Choice, 74, 389-403.

Blundell, R., Bond, S. (1998). Initial conditions and moment restrictions in dynamic panel data models. Journal of Econometrics, 87, 115-143.

Brasil. Constituição, 1988.

. Lei Complementar $n^{\circ} 101$, de 04 de maio de 2000.

Brollo, F.; Nannicini, T. (2012). Tying your enemy's hands in close races: the politics of federal transfers in Brazil. American Political Science Review, 106, p. 742-761.

Chattopadhyay, R., Duflo, E. (2004). Women as policy makers: evidence from a randomized policy experiment in India, Econometrica, 72(5), p. 1409-1443.

Rev. Text. Econ., Florianópolis, v. 21 n. 1, p. 01 -24, dez/mar. 2018 ISSN 2175-8085 
Chortareas, G.; Logothetis, V.; Papandreou, A. A. (2016). Political budget cycles and reelection prospects in Greece's municipalities. European Journal of Political Economy, 43, p. $1-13$.

Corneo, G.; Gruner, H. P. (2002). Individual preferences for political redistribution. Journal of Public Economics, 83, p. 83-107.

Drazen, A., Eslava, M. (2010). Electoral manipulation via voter-friendly spending: theory and evidence. Jornal of development economics 92, 39-52.

Ehrhart, H. (2013). Elections and the structure of taxation in developing countries. Public Choice, 156, 195-211.

Ferreira, F.; Gyourko, J. (2014). Does gender matter for political leadership? The case of U.S. mayors. Journal of Public Economics, 112, p. 24-39.

Ferreira, I. F. S.; Bugarin, M. S. (2007). Transferências voluntárias e ciclo políticoorçamentário no federalismo fiscal brasileiro. Revista Brasileira de Economia, 61(3), p. 271300.

Foremny, D.; Freier, R.; Moessinger, M. D.; Yeter, M. (2014). Overlapping political budget cycles in the legislative and the executive. Centre for European Economic Research Discussion Paper, 14-099.

Gadelha, S. R. B. (2012). Análise dos Impactos da Lei de Responsabilidade Fiscal sobre a despesa de pessoal e a receita tributária nos municípios brasileiros: em estudo com modelo probit aplicado a dados em painel. Textos para Discussão Tesouro Nacional, 3, p. 1-18.

Giambiagi, F.; Além, A. C. (2008). Finanças públicas: teoria e prática no Brasil. 3. ed. Rio de Janeiro: Campus.

Giuberti, A. C. (2006). Lei de Responsabilidade Fiscal: efeitos sobre o gasto com pessoal dos municípios brasileiros. In: Secretaria do Tesouro Nacional. (Org.). Finanças Públicas: Monografia premiada em $2^{\circ}$ lugar no X Prêmio Tesouro Nacional - 2005. São Paulo: Ágape Editores Ltda, p. 803-841.

Greene, W. (2012). Econometric analysis. 7th Edition: International Edition. Pearson.

Hansen, L. P. (1982). Large sample properties of generalized method of moment's estimator. Econometrica, 50(4), 1029-1054.

Hayo, B.; Neumeier, F. (2012). Leaders' Impact on Public Spending Priorities: The Case of the German Laender. KYKLOS, 65(4), p. 480-511.

; . (2014). Political leaders' background and fiscal performance in Germany. European Journal of Political Economy, 34, p. 184-205.

Hibbs, D. (1977). Polítical parties and macroeconomic policy. The American Political Science Review, 7, p. 1467-148. 
Jacobsen, D. I. (2006). Public sector growth: comparing politicians' and administrators' spending preferences. Public Administration, 84(1), p. 185-204.

Katsimi, M.; Sarantides, V. (2012). Do elections affect the composition of fiscal policy in developed, established democracies? Public Choice, 151, 325-362.

Klein, F. A. (2010). Reelection incentives and political budget cycle: evidence from Brazil. Revista de Administração Pública, 44(2), p. 283-337.

; Sakurai, S. N. (2015). Term limits and political budget cycles at the local level: evidence from a young democracy. European Journal of Political Economy, 37, 21-36.

Kneebone, R. D.; Mckenzie, K. J. (2001). Electoral and partisan cycles in fiscal policy: an examination of Canadian provinces, Internation Tax and Public Finance, 8, 753-774.

Lautenschlage, J. (2016). Políticos, eleições e receitas públicas. Textos de Economia, 19(1), 24-47.

. (aceito para publicação). Impacto da Lei de Responsabilidade Fiscal sobre os ciclos político-orçamentários e os níveis de despesas e receitas nos estados brasileiros. Economic Analysis of Law Review.

Mainwaring, S. P. (1999). Rethinking party systems in the third wave of democratization: the case of Brazil. Stanford University Press.

Martínez-Bravo, M. (2017). The local political economy effects of school construction in Indonesia. American Economic Journal: Applied Economics, 9(2), p. 256-289.

Morozumi, A.; Veiga, F. J. e Veiga, L. G. (2014). Conditional electoral effects on the composition of public expenditures and revenue: evidence from a large panel of countries. NIPE-WP 23/2014.

Nakaguma, M. Y.; Bender, S. (2006). A Emenda da Reeleição e a Lei de Responsabilidade Fiscal: impactos sobre ciclos políticos e performance fiscal dos estados (1986-2002). Economia Aplicada, v. 10, n. 3, p. 377-397.

Nordhaus, W. (1975). The polítical business cycle. Review of Economic Studies, 42, 169-190.

Park, S. (2014). The politics of redistribution in local governments: the effect of gender representation on welfare spending im California counties. Journal of Public Policy, 34(2), p. 269-301,.

Potrafke, N. (2012). Political cycles and economic performance in OCDE countries: empirical evidence from 1951-2006. Public Choice, 150, 155-179.

Rezende, F. (1995). Federalismo fiscal no Brasil. Revista de Economia Política, 15 (3), 5-17.

Rogoff, K. (1990). Equilibrium polítical budget cycles. American Economic Review, 80, 2136. 
Rogoff, K.; Sibert, A. (1988). Elections and macroeconomic policy cycles. Review of Economics Studies, 55, 1-16.

Sakurai, S. N. (2009). Ciclos políticos nas funções orçamentárias dos municípios brasileiros: uma análise para o período 1990 - 2005 via dados em painel. Estudos Econômicos, 39(1), p. $39-58$.

; Menezes-Filho, N. (2008). Fiscal policy and reelection in Brazilian municipalities. Public Choice, 137, p.301-314.

; Menezes-Filho, N. (2011). Opportunistic and partisan election cycles in Brazil: new evidence at the municipal level. Public Choice, 148, p. 233-247.

Seitz, H. (2000). Fiscal policy, deficits and politics of subnational governments: The case of the German Laender. Public Choice, 102, 183-218.

Serra, J.; Afonso, J. R. R. (1999) O federalismo fiscal à brasileira: algumas reflexões. Revista do BNDES, 12 (6), 3-30.

Tellier, G. (2006). Public expenditures in Canadian provinces: An empirical study of políticoeconomic interactions. Public Choice, 126, 367-385.

Vasconcelos, R. D.; Ferreira Jr, S.; E Nogueira Jr, R. P. (2013). A dinâmica da execução orçamentária federal do Brasil sob a ótica dos ciclos políticos eleitorais, 1985-2010. Economia Aplicada, 17(3), p. 325-354.

Veiga, L. G.; Veiga, F. J. (2007). Polítical business cycles at the municipal level. Public Choice, 131, 45-64.

from a Natural Experiment. NIPE - WP 07/2016

Vergne, C. (2006) Democracy, Elections and Allocation of Public Expenditure in Developing Countries. European Journal of Political Economy, 25, 63-77.

Vicente, C.; Benito, B.; Bastida, F. (2013). Transparency and political budget cycles at municipal level. Swiss Political Science Review, 19(2), 139-156.

Windmeijer, F. (2000). A finite sample correction for the variance of linear two-step GMM estimators. Institute of Fiscal Studies Working Paper Series No W00/19.

Yoo, K. R. (1998). Intervention analysis of electoral tax cycle: the case of Japan. Public Choice, n. 96, p. 241-258.

Zucco, C. (2011). Esquerda, Direita e Governo: A Ideologia dos Partidos Políticos Brasileiros, in T. Power e C. Zucco (orgs.), O Congresso por Ele Mesmo: Autopercepções da Classe Política Brasileira. Belo Horizonte, Ed. UFMG. 